NASA Technical Memorandum 102374

AIAA-89-1060

\title{
$\therefore=5=$ \\ Prediction of Unsteady Blade Surface Pressures on an Advanced Propeller at an Angle of Attack
}

M. Nallasamy

Sverdrup Technology, Inc.

NASA Lewis Research Center Group

Cleveland, Ohio

and

J.F. Groeneweg

National Aeronautics and Space Administration

Lewis Research Center

Cleveland, Ohio

November 1989 



\section{PREDICTION OF UNSTEADY BLADE SURFACE PRESSURES ON AN \\ ADVANCED PROPELLER AT AN ANGLE OF ATTACK \\ M. Nal lasamy* \\ Sverdrup Technology, Inc. \\ NASA Lewis Research Center Group \\ Cleveland, Ohio 44135 \\ and \\ J.F. Groeneweg** \\ National Aeronautics and Space Administration \\ Lewis Research Center \\ Cleveland, Ohio 44135}

\section{ABSTRACT}

The paper considers the numerical solution of the unsteady, three-dimensional, Euler equations to obtain the blade surface pressures of an advanced propeller at an angle of attack. The specific configuration

considered is the SR7L propeller at cruise conditions with a $4.6^{\circ}$ inflow angle corresponding to the $+2^{\circ}$ nacelle tilt of the Propeller Test Assessment (PTA)

o flight test condition. The results indicate nearly sinusoidal response of the blade loading, with angle of attack. For the first time, detailed variations of the chordwise loading as a function of azimuthal angle are presented. It is observed that the blade is lightly loaded for part of the revolution and shocks appear from hub to about 80 percent radial station for the highly loaded portion of the revolution.

\section{INTRODUCTION}

Advanced propeller tests in wind tunnels and in flight have been conducted to understand the aerodynamics and acoustics of advanced designs.

*Senior Supervisor, Aeromechanics Department.

**Chief, Propeller and Acoustics Technology Branch, Propulsion System Division. 
Aerodynamic tests of the 9-ft dlameter, single rotation SR7L NASA/Hamilton standard design were run in the ONERA S1-MA wind tunnel in Modane, France. Blade surface steady and unsteady pressures were measured during early 1987 on a two blade configuration. ${ }^{1-3}$ (The complete eight blade propeller was not tested due to drive power limitations.) The propfan test assessment filght program (1987-1988) was managed by Lockheed Aeronautical Systems Company under a contract to the NASA Lewis Research Center. The 9-ft propfan was flight tested on a modified, instrumented Gulfstream GII business jet (Fig. 1). The objectives of the PTA program were to evaluate the propfan structural integrity, source noise, cabin noise, flyover noise and enroute nolse. Thus, an extensive data base has been established for the development and validation of propfan aerodynamic and acoustic analyses.

In the PTA flight test program, the propfan propulsion system was mounted on the left wing of the modified GII alrcraft. This location was chosen to avoid flow field interference with the main propulsion Gulfstream engines and to permit systematic investigation of the propfan characteristics. ${ }^{4} \mathrm{~A}$ nacelle tilt arrangement was employed to vary the inflow angle to the propfan. The varlations in inflow conditions were used to evaluate the effects on cyclic stress of the propfan over a wide range of operating conditions. The inflow conditions also play an important role in the generation of noise. The three nacelle tilt angles of the test were $-3^{\circ},-1^{\circ}$ ( $t i 1 t$ down) and $+2^{\circ}$ ( $t i 1 t$ up). The average inflow angle is dependent on the alrplane angle of attack, propfan upwash angle and nacelle tilt. The complete nacelle tilt variation of $5^{\circ}\left(-3^{\circ}\right.$ to $+2^{\circ}$ ) provided an inflow angle variation of $5^{\circ} .5^{5}$

Acoustic and performance data were acquired over a wide range of operating conditions. The test points were specifically chosen to determine the near field noise characteristics as a function of flight Mach number, altitude, propfan tip speed, power and inflow angle. 
The near field acoustic data for the baseline design-point crutse $\langle M=0.8)$ case of $-1^{\circ}$ nacelle tilt have been analyzed in detail.5 The acoustic data measured on a wing boom outboard of the propfan show that the first five harmonics have maximum sound pressure levels (SPL's) in the plane of the propfan. The SPL's decrease in level with increase in harmonic order and all have similar directional characteristics. The sound pressure levels were also predicted using Hanson's frequency domain propeller noise radiation theory. 6 The predictions show that the SPL levels are maximum at 0.25 dlameter aft of the propeller plane. The levels are overpredicted by about 3 $d B$.

The effects of nacelle tilt on the fuselage and wing boom SPL's were studied both at the cruise and takeoff conditions. Increasing nacelle tilt resulted in significant reductions in SPL at the fuselage for all tip speeds. At the wing boom, the SPL's were found to increase with increase in tilt angle. On the average an acoustic sensitivity of about $1 \mathrm{~dB} /$ degree of nacelle tilt was observed. Predictions of the SPL's for the nacelle tilt test cases were also done by Hamilton Standard; however, the predicted fuselage and wing boom SPL's showed very little sensitivity to nacelle tilt angle.

Prediction of the effect of inflow angle on the sound pressure levels requires accurate computation or measurement of the unsteady blade surface pressures. The linear analytical methods for computing the unsteady blade loading may not predict the loading accurately enough at higher inflow angles due to nonlinear processes involved. In the present paper, the unsteady blade pressures are computed by numerically solving the three-dimensional unsteady Euler equations. The only published three-dimensional unsteady Euler solution for the propeller at angle of attack is that of Witfield et al.7 The emphasis In that work was on validation of the solution algorithm for different configurations. The present paper provides, for the first time, detalled 
unsteady Euler solutions of the propeller at an angle of attack. The angle of attack induced unsteadiness is fllustrated in the form of chordwise, spanwise and azimuthal pressure distributions.

\section{SOLUTION OF THE UNSTEADY EULER EQUATIONS}

The unsteady three-dimensional Euler equations governing the inviscid flow through a propeller are solved using the solution procedure developed by Whitfield.7,8 (The detalls may be found in the references cited. Here only a brief mention of the technique will be made.) The equations in conservative differential form are transformed from a Cartestan reference frame to a time dependent body fitted curvilinear reference frame. The transformed equations are discretized employing a finite volume technique. An approximate Riemann solver is used for block interface flux definitions. A Lower-Upper (LU) implicit numerical scheme which possesses apparent unconditional stability is used to solve the discretized equations. The flow field is represented by multiblock composite grids to overcome computer core memory limitations. The solution at each time step is updated by having only one block in memory while the other blocks are stored in solid-state storage devices (SSD).

THE FLOW CONFIGURATION AND COMPUTATIONAL GRID

The configuration considered here is the eight blade 9-ft diameter SR7L propeller (Fig. 1), of the PTA program. The inflow angle chosen for the present computations is $4.6^{\circ}$ (corresponding to nacelle tllt of $+2^{\circ}$ in the PTA program). The direction of rotation of the propeller and the reference for the coordinates are shown on the side of the figure.

Each blade passage is discretized employing a 71 by 33 by $11 \mathrm{grid}$, in the axial, radial and circumferential directions, respectively. Each passage grid is divided into two blocks for computational convenience as mentioned before. Thus, 16 blocks of grids are employed to describe the entire propeller flow 
field with 206,184 nodal points. Each blade surface has 35 by 21 (chordwise by spanwise) grid points with higher resolution near the leading and trafling edges. The solution presented here is for the cruise condition, Mach number $=$ 0.801 and advance ratio 3.122 , with an inflow angle of $4.6^{\circ}$.

RESULTS AND DISCUSSION

The unsteady three-dimensional Euler equations have been solved (from an impulse start) for three complete revolutions of the propeller to get a reasonably accurate solution. The results of the third cycle are fairly stabilized as can be seen from Fig. 2. The figure shows the variation of the total power coefficient with azimuth angle. The total power coefficient becomes nearly constant during the entire third revolution of the propeller. The results of this cycle are analyzed further and presented. The predicted total power is about 8 percent higher than the measured value. No chordwise pressure measurements are available for a direct comparison of the predictions. However, the predictions of unsteady surface pressures employing the present solution technique were compared with data for SR3 elght bladed model propeller in Ref. 7 (Fig. 5). The comparisons were done at blade chord location $x / c=0.1$ and 0.5 at blade span locations 0.75 and 0.88 radius for an inflow angle of $4^{\circ}$ at Mach numbers 0.6 and 0.8 . At the axial station $x / c=0.5$ the agreement of the predictions with measurements were very good on both suction and pressure surfaces at Mach numbers 0.6 and 0.8 . At the axial location $x / c=0.1$, predicted surface pressures showed reasonable agreement with data for $M=0.6$ on both, suction and pressure surfaces. At the higher Mach number, 0.8 , the pressure side was in reasonable agreement with the experiment but the suction side was not. The discrepancy was attributed to the coarse grid near the leading edge for the rapidly expanding flow on the suction surface at this Mach number. In Ref. 7, 21 (axial) by 12 (radial) 
grid points on the blade were employed. With 35 (axial) by 21 (radial) grid points on the blade surface and higher resolution near the leading and trafling edges, employed in the present study a higher accuracy of the predictions is expected. The grid size and distribution were arrived at during the comparison study of steady Euler solutions with measurements for the SRTL two bladed configurations over a range of Mach numbers. ${ }^{9}$

Figure $3(a)$ shows the varlation of the single blade power coefficient with azimuth angle for two blades, one starting from $\phi=0$ (or $\phi_{S}=0$ ) position and other starting from $\phi=\pi\left(\right.$ or $\left.\phi_{S}=\pi\right)$. The expected sinusoldal variation of the loading due to angle of attack $\left(\alpha=4.6^{\circ}\right)$ is clearly exhibited. However, the variation of power during a cycle is significantly higher than one might expect. For the case of $4.6^{\circ}$ inflow angle, the power coefficlent per blade varies +81 percent during a cycle. A careful look at the plot reveals additional detalls: the loading is not exactly sinusoidal; the loading is not minimum at $\phi=0$ and the maximum in not at $\phi=\pi$ as originally believed. The rising portion of the wave lasts for about $9 / 8 \pi$ while the falling portion of the wave last about $7 / 8 \pi$. For the blade starting at $\phi=0$, the minimum loading occurs at $\pi / 8$ and the maximum loading occurs at about $(\pi / 8+9 / 8 \pi=5 / 4 \pi)$ or $225^{\circ}$. These points have to be borne in mind during the analysis of the results.

A Fourier transform on the third cycle loading gives the blade power coefficient $C p$ as $C p=0.238-0.1987$ cos $w t-0.0511$ sin wt. The loading spectrum shown in Fig. $3(b)$ indicates that the first harmonic dominates the loading. The osclllating part of the $C p$ lags behind the motion of the blade by $14.4^{\circ}$.

The reduced frequency, which is a measure of the unsteadiness of the flow is defined as, $k=w c / 2 U_{\infty}$, where $c$ is the blade chord length, $w$ is the 
blade rotational frequency and $U_{\infty}$ is the free stream velocity. The reduced frequency for the present calculations is $k=0.088$, based on the chord length at 75 percent radius.

For comparison purposes a steady state solution was obtained for the same advance ratio (3.122) and Mach number $(0.801)$ but with zero angle of attack. The steady blade surface pressure distributions are shown in Fig. 4. The figure shows chordwise pressure distributions at elght spanwise locations. The unsteady blade surface pressure distributions presented in the succeeding figures will be at one or more of these spanwise locations. Thus, a direct comparison of the steady and unsteady pressure distributions can be made.

The detailed azimuthal variations of the chordwise loading and blade surface pressure distributions are illustrated in Figs. 5 to 10 for three radial stations namely, $r / R=0.36,0.66$ and 0.96 . Figure 5 presents the chordwise loading variations as a function of azimuth angle, at the radial station $r / R=0.36$. At this radial station, the blade is negatively loaded for the front half ( 0 to 50 percent) of the cord length for about $3 / 8$ of a revolution $\left(\phi=0^{\circ}, 45^{\circ}, 90^{\circ}\right)$ and the loading is maximum at $\phi=225^{\circ}$. Thus, the chordwise loading undergoes a cyclic varlation of substantlal amplitude. The shape of the loading curve also changes enormously during the cycle. The reasons for this change become apparent from the actual blade surface pressures shown in Fig. 6 for the same radial azimuthal locations. The trailing edge shock appears on the suction surface during half the cycle $\left(\phi=135^{\circ}\right.$ to $\left.270^{\circ}\right)$ while the shock appears on (or extends to) the pressure surface for $\phi=135^{\circ}$ to $225^{\circ}$. The dramatic changes in the loading pattern are clearly illustrated in this figure.

Figure 7 shows the azimuthal variation of chordwise loading distribution at $r / R=0.66$. The part of the revolution during which significant negative 
loading exists, is reduced for this radial station. A continuous change of the space of the loading curve occurs over the revolution. The second half (50 to 100 percent chord) of the blade is highly loaded from $\phi=90^{\circ}$ to $225^{\circ}$. The blade surface pressures shown in Fig. 8 indicate the appearance of the trailing edge shock for $\phi=90^{\circ}$ to $270^{\circ}$ and a pressure jump on the pressure side occurs only for $\phi=90^{\circ}$ to $225^{\circ}$. Thus, for the two radial stations $(0.36$ and 0.66$)$, the shocks appear only during parts of the cycle. It is also interesting to note that the shock on the pressure surface moves upstream as we go from $\phi=90^{\circ}$ to $225^{\circ}$.

The periodic motion of shock waves on oscillating airfoils in transonic flow have been extensively studied and documented. 10 Three types of shock motion have been identified; (1) Sinusoldal shock-wave motion (type A): The shock-wave moves almost sinusoidally and exists during the complete cycle. (2) Interrupted shock-wave motion (type $B$ ): This motion is like type $A$ but the shock disappears during part of a cycle and (3) Upstream propagated shock-wave (type c): At silightly super critical Mach Numbers, periodically a shock-wave is formed on the upper surface of the airfoll and moves upstream while increasing in strength. No such detailed experimental study exists for the three-dimensional transonic flows of the type considered in this paper. But, the results presented in Figs. 6 and 8 suggest that shock motions similar to type $B$ and type $C$ occur in the unsteady three-dimensional transonic flows.

The azimuthal variation of chordwise loading at the radial station $r / R=0.96$ is shown in Fig. 9. At this radial station, the changes in the shape of the loading curve are marginal, compared to those at $r / R=0.36$ and 0.66 . However, the location of the maximum loading moves from a point close to the trailing edge to a point near the leading edge as we go from $\phi=45^{\circ}$ to $\phi=315^{\circ}$. The blade surface pressure variations shown in Fig. 10, indicate 
that the shocks have diffused before they reached this radial station. It is interesting to note that the tip region is significantly loaded through the complete revolution of the blade.

Figures 11 to 14 show the radial varlation of the chordwise pressure distribution for four azimuthal angles, $\phi=0^{\circ}, 90^{\circ}, 180^{\circ}$ and $270^{\circ}$

respectively. The radial variations of the chordwise loading distribution at $\phi=0^{\circ}$ are shown in Fig. 11. At this azimuthal location the blade is very lightly loaded throughout the span. A small negative loading exists almost up to $r / R=0.80$, which is due to the low local flow incidence angle produced by the angle of attack of the propeller. Figure 12 shows the radial variations of the chordwise pressure distributions at $\phi=90^{\circ}$. At this azimuthal location, shocks exist both on the suction and pressure surfaces from the hub region to almost 90 percent span. Up to 80 percent span the loading is primarily on the rearward half (50 to 100 percent chord) of the blade.

The spanwise varlation of the loading at $\phi=180^{\circ}$ is shown in Fig. 13 . At this location the blade loading experiences a near maximum. At this azimuthal location also, shocks appear on both suction and pressure surfaces from the hub region. However, on the suction surface the traliling edge shock is diffused beyond about 62 percent span. The shock on the pressure surface persists to 80 percent span, as for the $\phi=90^{\circ}$ position. Figure 14 shows the spanwise variations of the loading for $\phi=270^{\circ}$. At this location no shock exists on the pressure side of the blade. On the suction surface, a shock appears at about 70 percent chord at the radial station near the hub, $r / R=0.36$. With increasing spanwise distance, the shock moves toward the trailing edge. The four figures (Figs. 11 to 14) demonstrate that the blade loading changes significantly in the chordwise, radial and azimuthal directions during a revolution, due to the angular inflow to the propeller. 
The variations of the elemental power coefficient $(d C p / d x)$ for the four azimuthal locations $\left(\phi=0^{\circ}, 90^{\circ}, 180^{\circ}\right.$ and $\left.270^{\circ}\right)$ are shown in Fig. 15. The general shape of the curve is the same as that obtained for a steady flow. The magnitude of $d C p / d x$ at any radial distance $(x=r / R)$ depends on the azimuthal location. Also shown in the figure is the curve for the steady flow $(a=0)$ solution. It is seen that the magnitude of the cyclic varlations of loading depends on the spanwise location.

The azimuthal variations of blade pressure coefficient at specified points along the chord at the radial station $r / R=0.66$ are shown in Fig. 16 . It can be seen that the response at the individual points $X / C=0.036,0.125$, $0.53,0.63$ and 0.84 is not exactly sinusoldal. The extent of the deviation from the sinusold depends on the chordwise location and the surface (suction or pressure surface) on which the point is located. The departure from the sinusoidal behavior may be due to the high inflow angle, and the presence of shock waves. It should also be noted that the instantaneous pressure coefficients are plotted in this figure rather than the fluctuations about the mean value of the pressure.

\section{CONCLUDING REMARKS}

A numerical solution of the unsteady three-dimensional Euler equations has been obtained for the flow through a propeller at an angle of attack to the mean flow. The results show the highly nonlinear nature of the loading variations during a revolution. For parts of the revolution the blade is very lightly loaded, while for other parts it is highly loaded with shocks appearing on both surfaces of the blade. The sound pressure levels, the directivity and the azimuthal variation will be studied next employing the unsteady blade pressure distribution obtained here. 


\section{ACKNOWLEDGEMENTS}

The authors wish to acknowledge the many helpful discussions with

Dr. D. Hoyniak and Messrs. M. Janus, D. Huff and B. Clark during this research.

The work of the first author (MN) was supported under contract NAS3-25266 with the NASA Lewis Research Center.

\section{REFERENCES}

1. Bushnel1, P. "Measurement of the Steady Surface Pressure Distribution of a Single Rotation Large Scale Advanced Propfan Blade at Mach Numbers from 0.03 to $0.78, "$ NASA CR-182124, July 1988.

2. Bushnel1, P., Gnuber, M. and Parzych, D., "Measurement of Unsteady Blade Surface Pressures on a Single Rotation Large Scale Advanced Propfan with Angular and Wake Inflow at Mach Numbers from 0.02 to 0.70 , NASA CR-182123, October 1988.

3. Cambel1, W.A. Wainauski, H.S. and Bushnel1, P.R., "A Report on High Speed Wind Tunnel Tests of the Large Scale Advanced Propfan," AIAA-88-2802, July 1988.

4. Poland, D.T., Bartel, H.W. and Brown, P.C., "PTA Flight Test Overview," AIAA-88-2803, July 1988.

5. Lockheed Aeronautical Systems Company, "Propfan Test Assessment: Flight Test Results Review, "NASA Lewis Research Center, November 14, 1988.

6. Hanson, D.B., "Near-Field Frequency Domain Theory for Propeller Noise," AIAA Journal, Vol 23, 1985, pp. 499-504.

7. Whitfield, D.L., Swafford, T.W., Janus, J.M., Mulac, R.A. and Belk, D.M., "Three Dimensional Unsteady Euler Solutions for Propfans and Counter Rotating Propfans," AIAA-87-1197, June 1987.

8. Janus, J.M. and Whitfield, O.L., "A Simple Time Accurate Turbomachinery Algorithm with Numerical Solutions of Uneven Blade Count Configuration," AIAA-88-0206, January 1989. 
9. Nallasamy, M., Yamamotto, 0., Warsi, S. and Bober, L.J., "Large Scale Advanced Propeller Blade Pressure Distributions: Prediction and Data", AIAA-89-2696, accepted for publication in the Journal of Propulsion and Power.

10. Tijdeman, H. and Seebass, R., "Transonic Flow Past Oscillating Airfoils," Annual Review of Fluid Mechanics, Vol, 12, 1980, pp. 181-222.

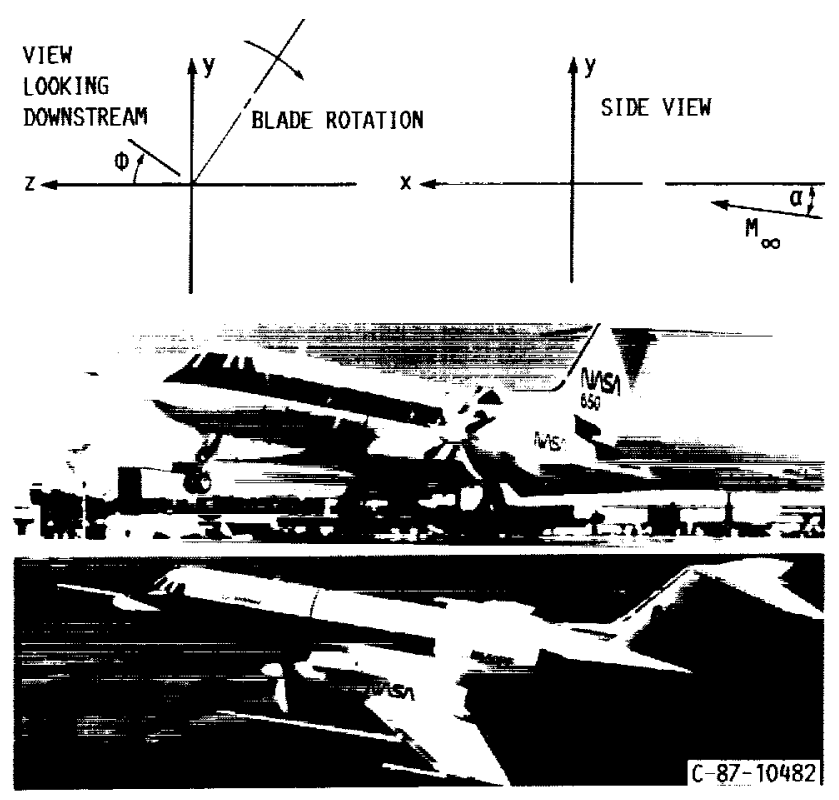

FIG. 1 SR7L PROPELLER INSTALLED ON THE TESTBED AIRCRAFT. 


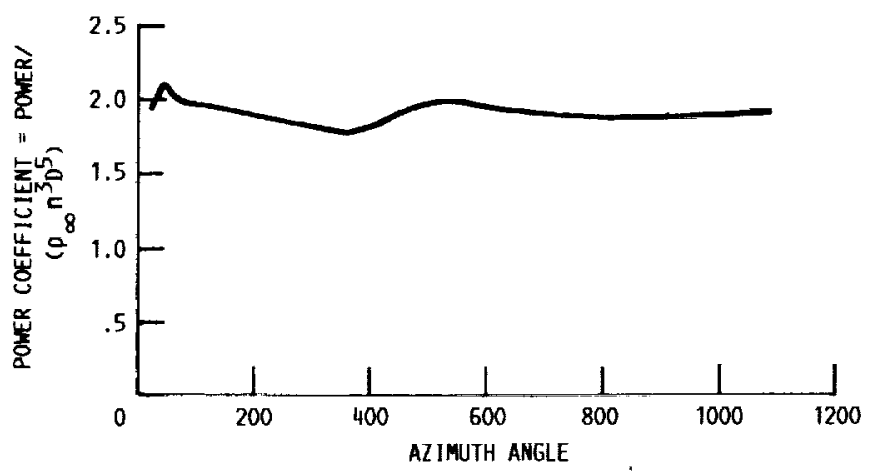

FIG. 2 TOTAL POWER COEFFICIENT VARIATION WITH AZIMUTH ANGLE.

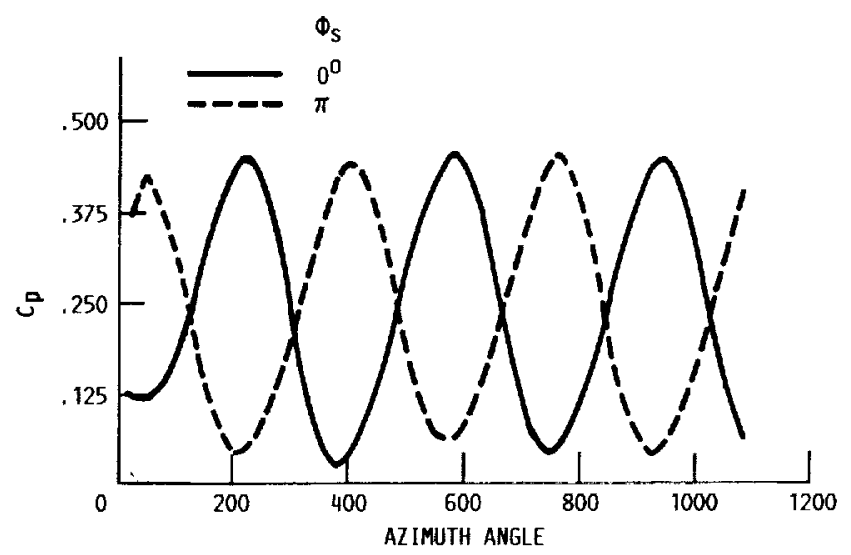

(a) POWER PER BLADE VARIATION WITH AZIMUTH ANGLE.

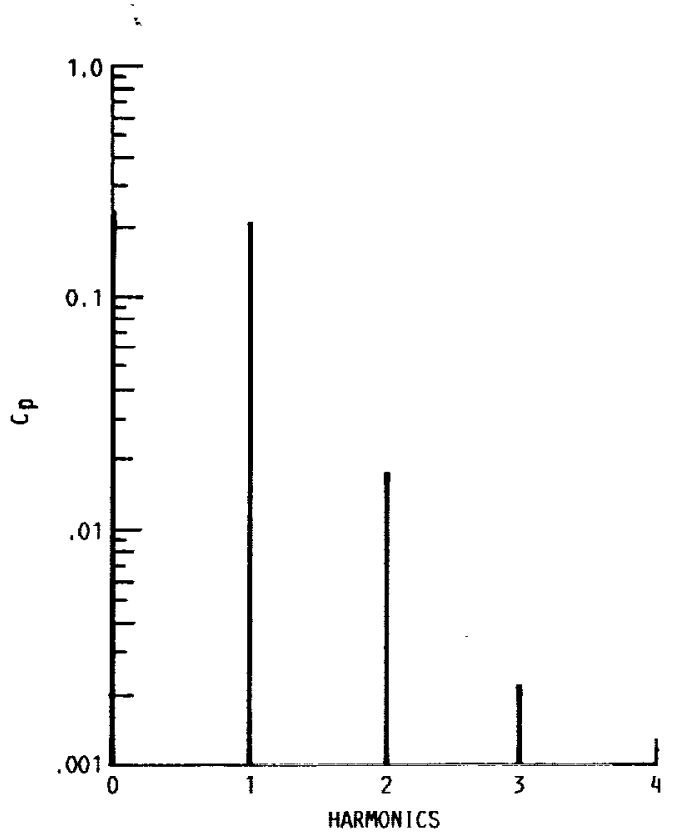

(b) LOADING SPECTRUM.

FIG. 3 

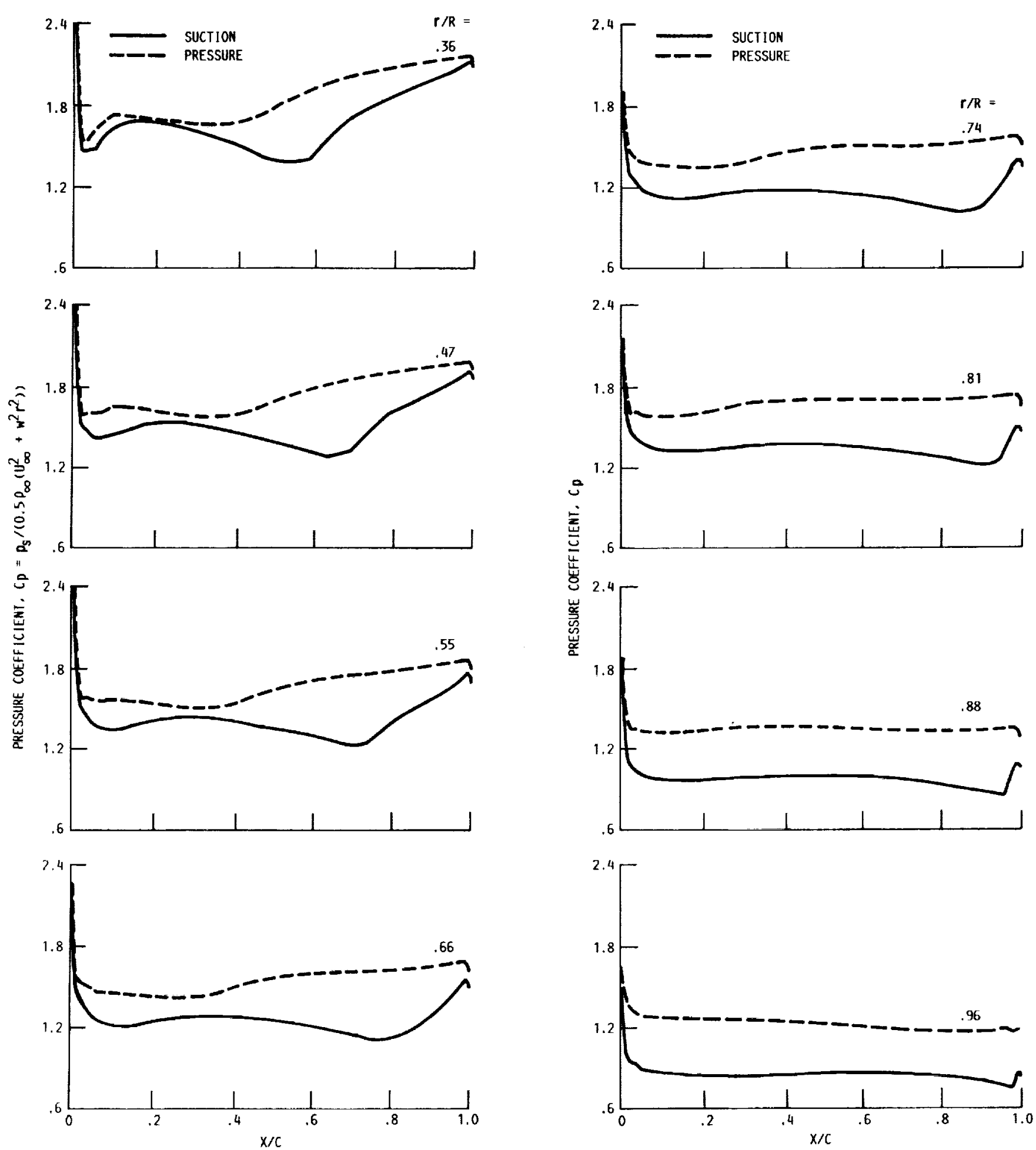

FIG, 4 STEADY $(\boldsymbol{a}=0)$ BLADE SURFACE PRESSURE DISTRIBUTINN.

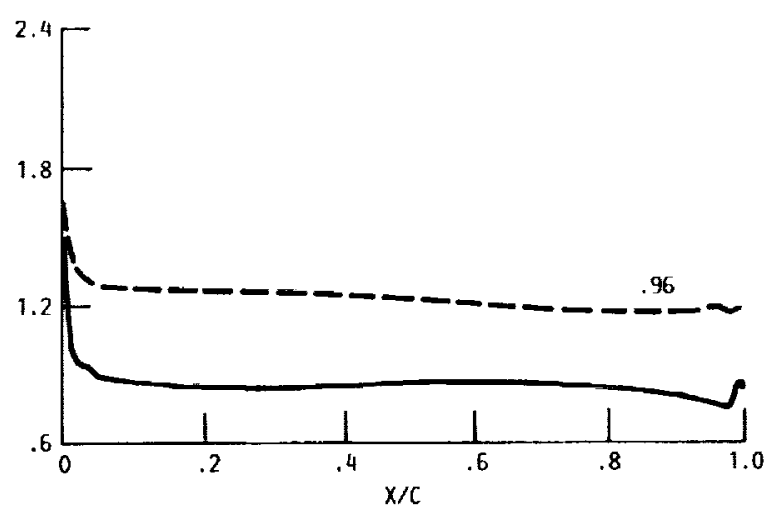

FIG. 4 CONCLUDED. 

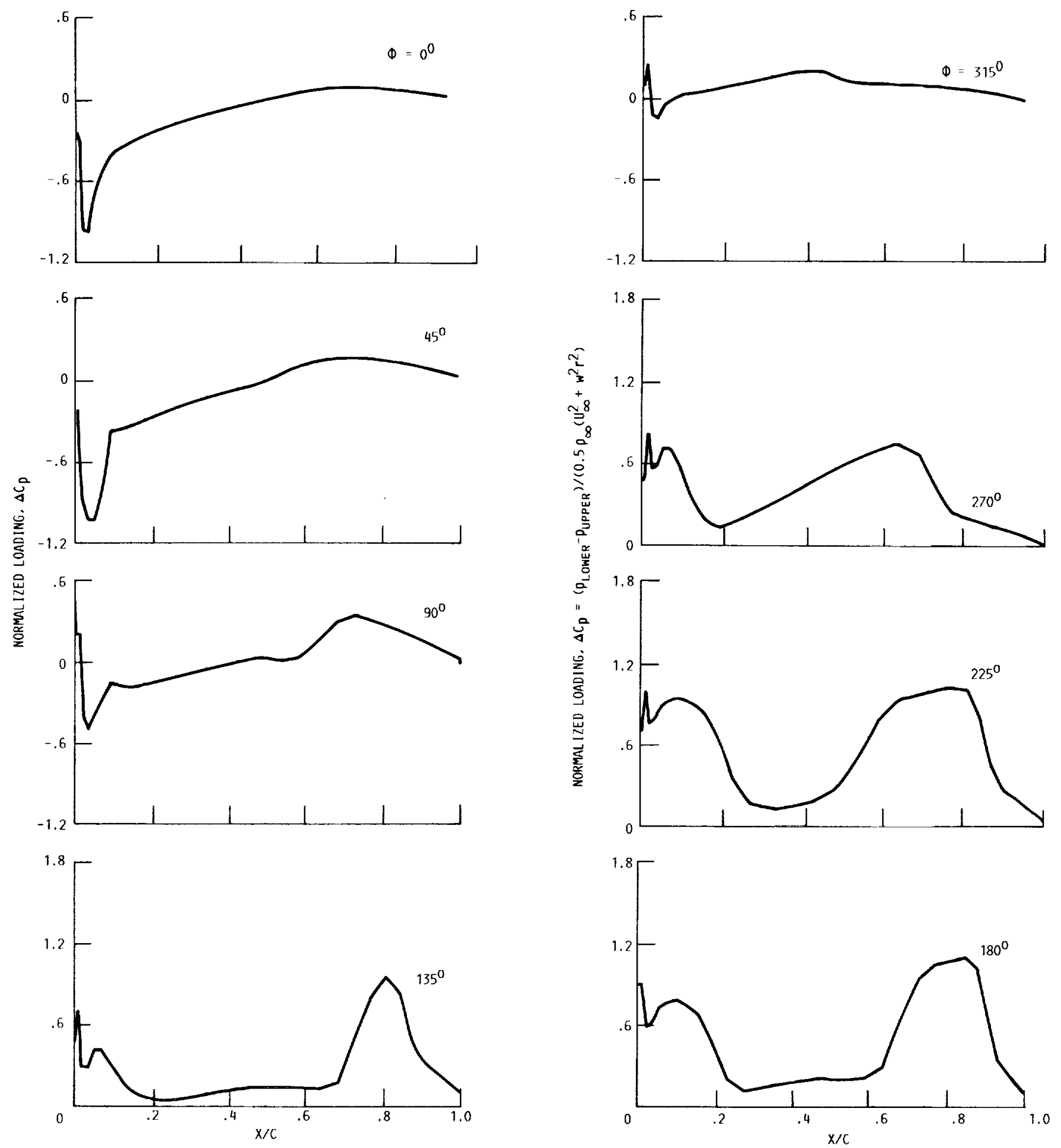

TIG. 5 NZIMUTHAL VARIATION OF CHORDWISE LOADING AT $r / R=0.36$.

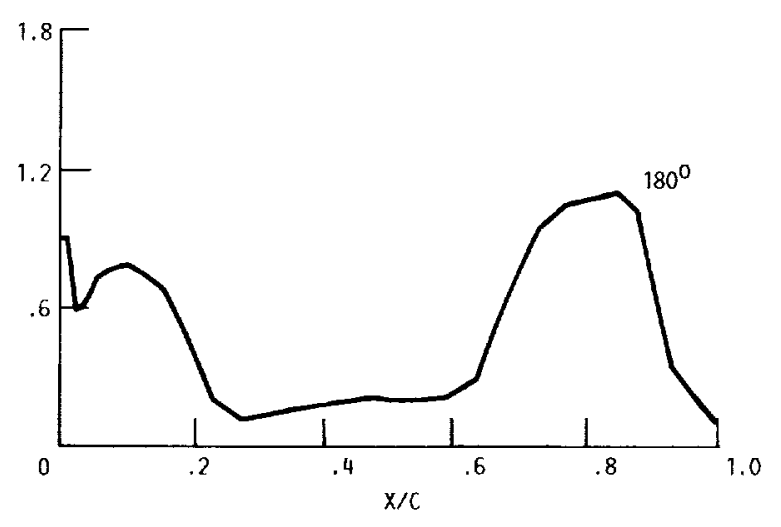

FIG, 5 CONCLUDED. 

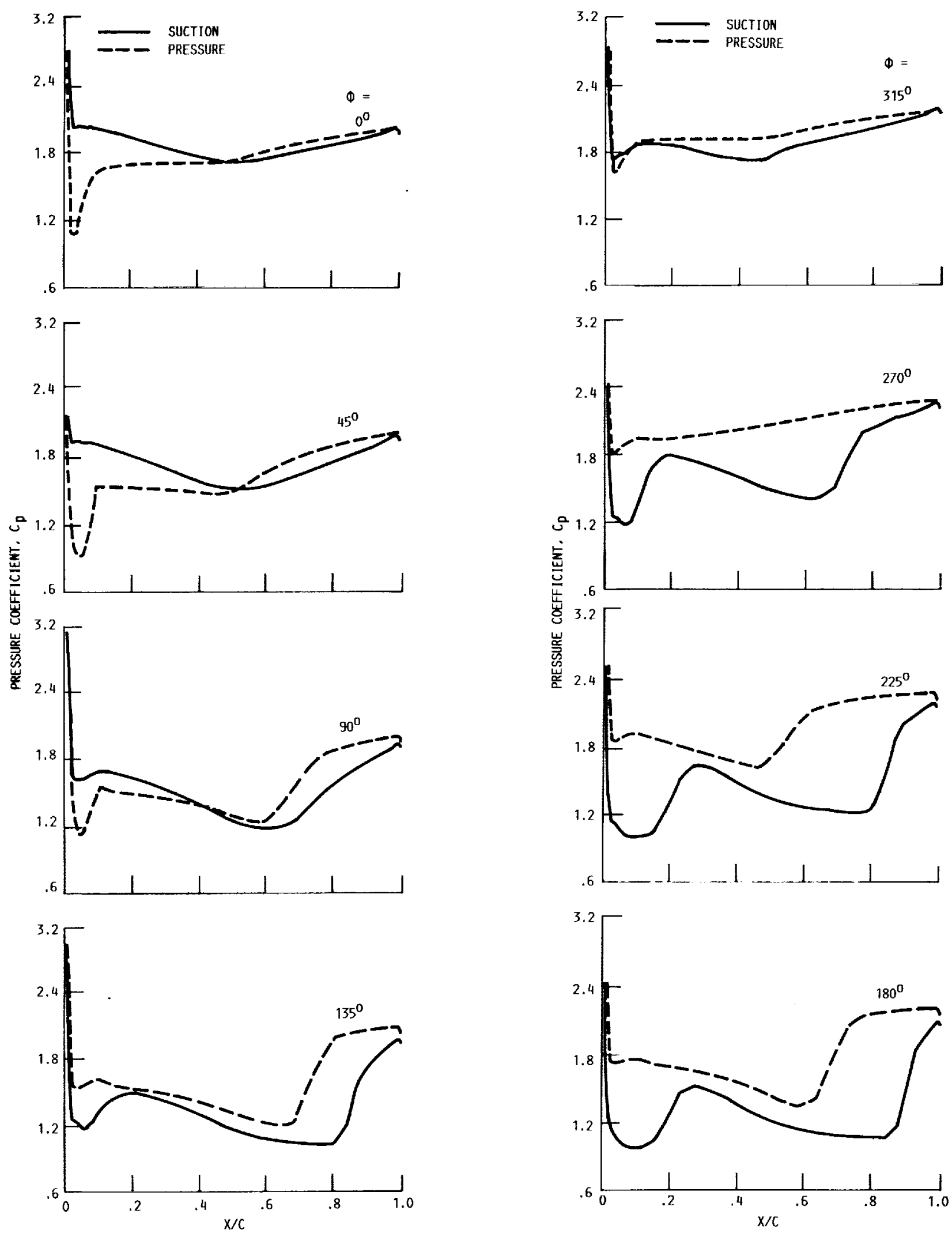

FIG, 6 AZIMUTHAL VARIATION OF BLADE SURFACE PRESSURES AT $\mathrm{r} / \mathrm{R}=0.36$.

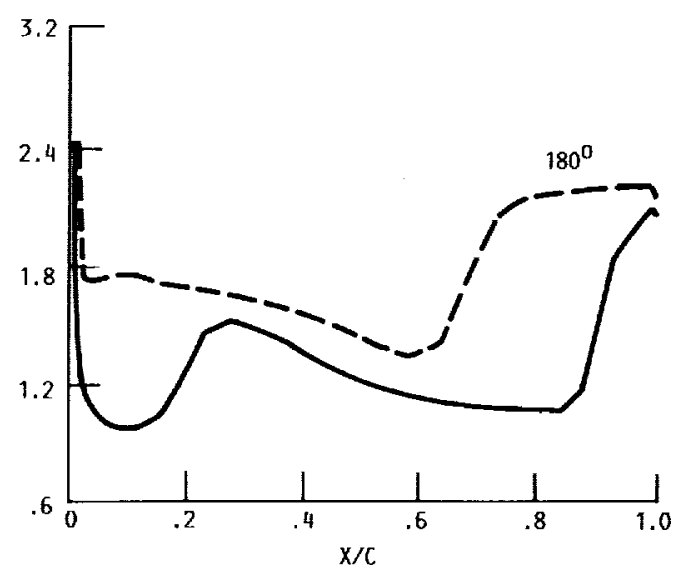

FIG. 6 CONCLUDED. 

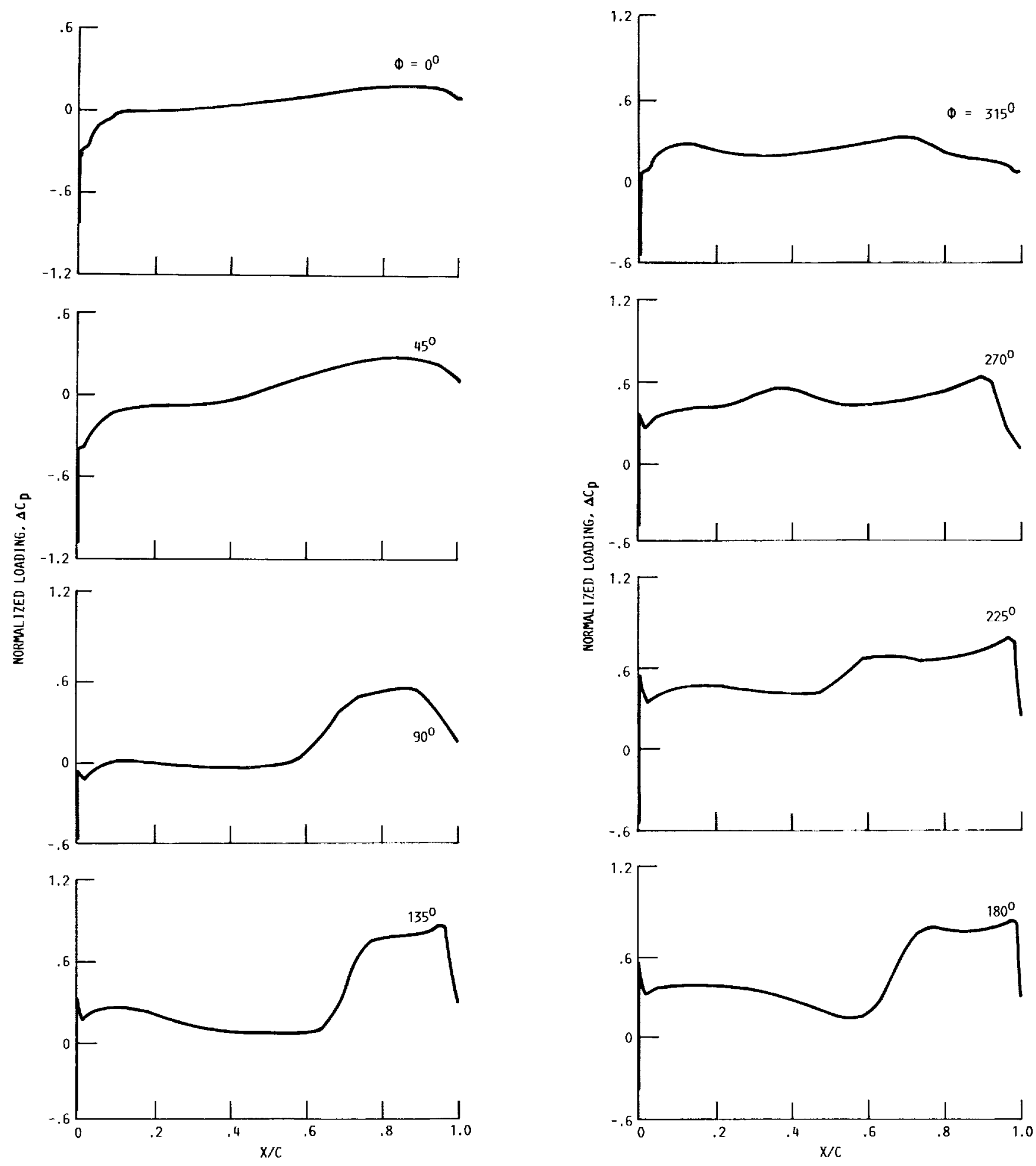

FIG. 7 AZIMUTHAL VARIATION OF CHORDWISE LOADING AT $r / R=0.66$.

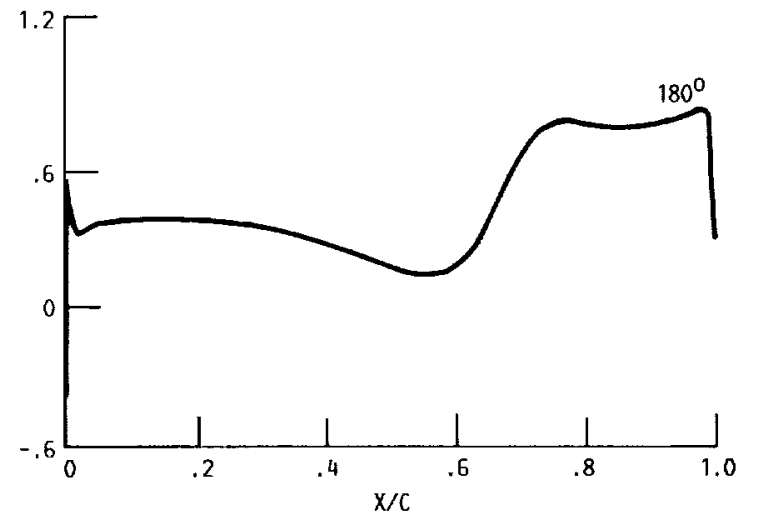

FIG. 7 CONCLUDED. 

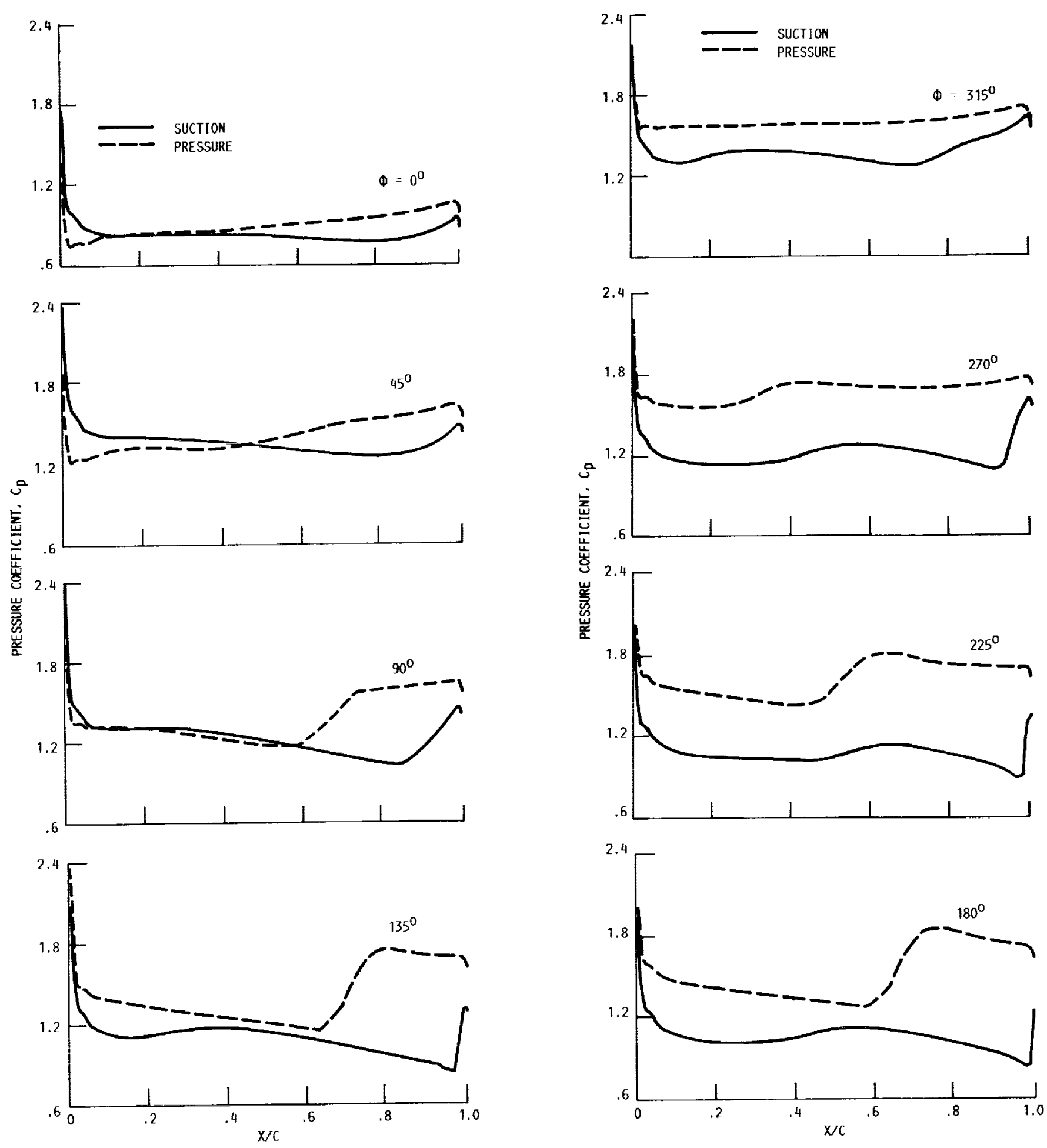

FIG. 8 AZIMUTHAL VARIATION OF BLADE SURFACE PRESSURES AT $r / R=0.66$.

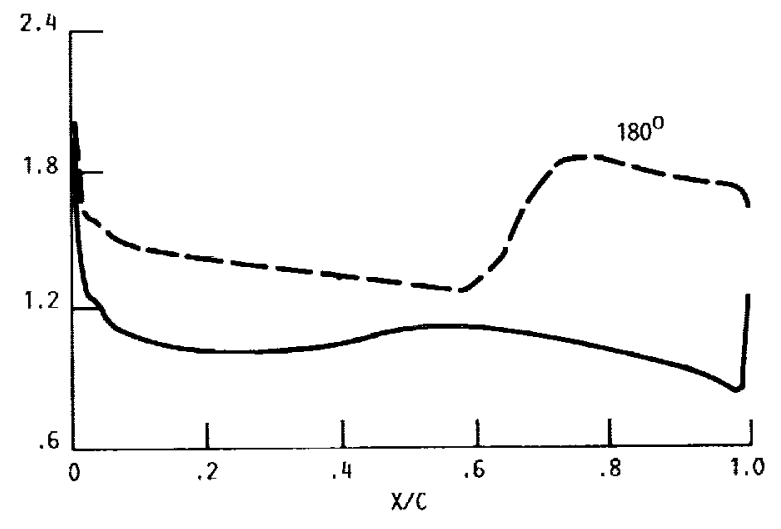

Fig. 8 CONCLUDED. 

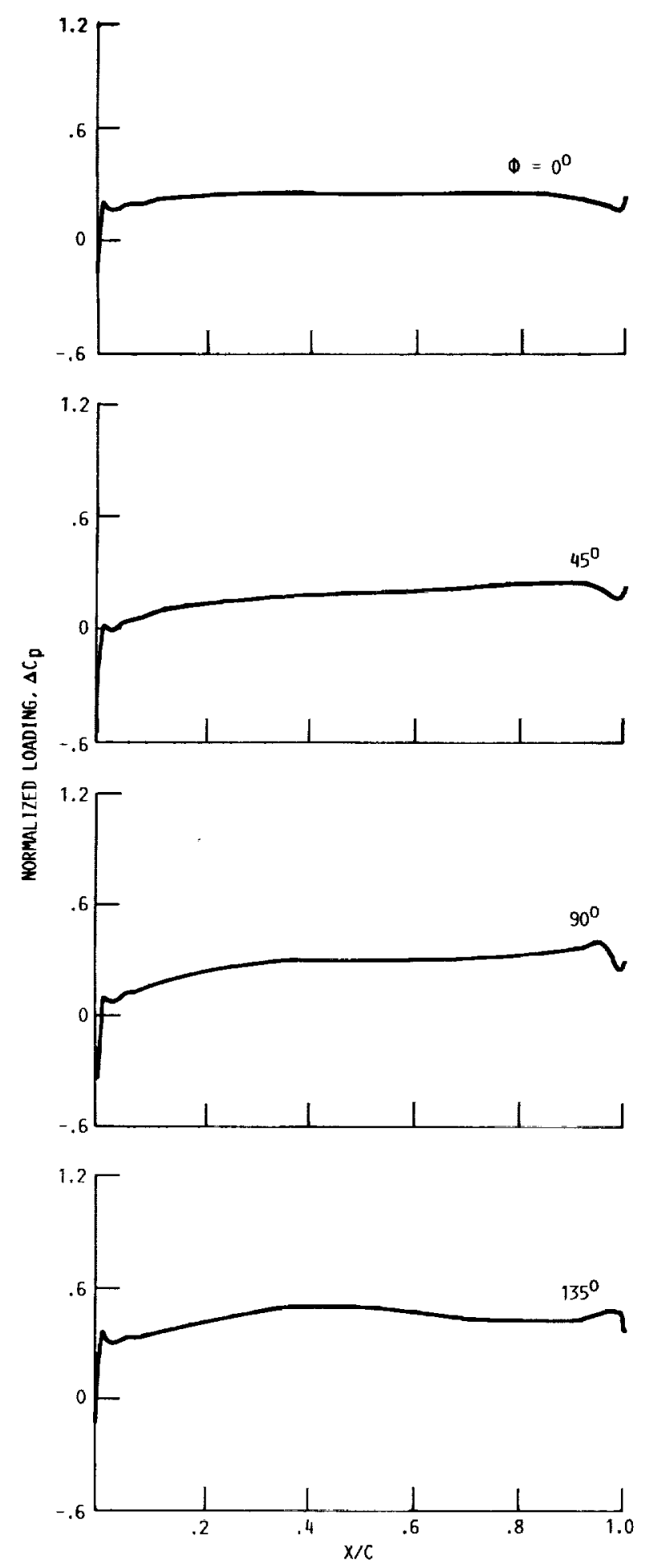

FIG. 9 AZIMUTHAL VARIATION OF CHORDWISE LOADING AT $r / R=0.96$.
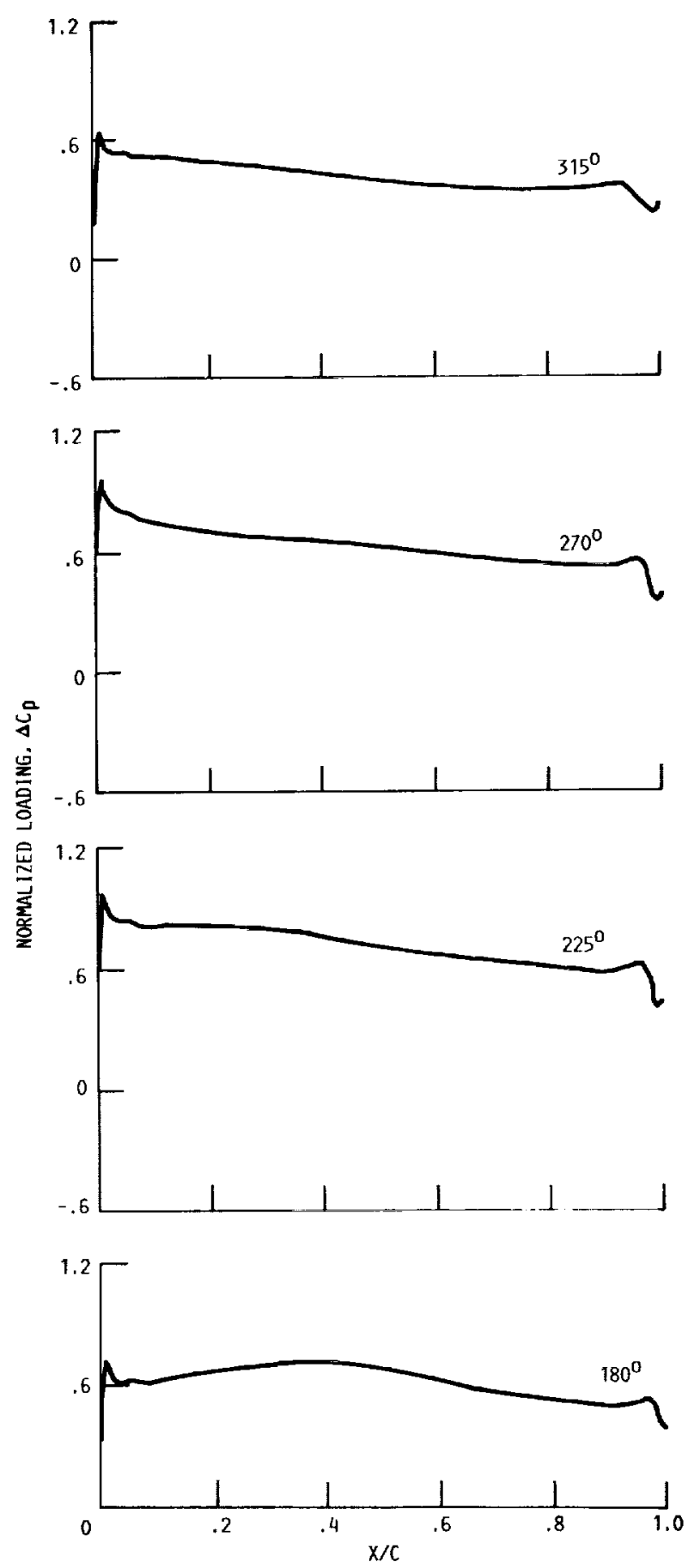

FIG. 9 CONCLUDED. 

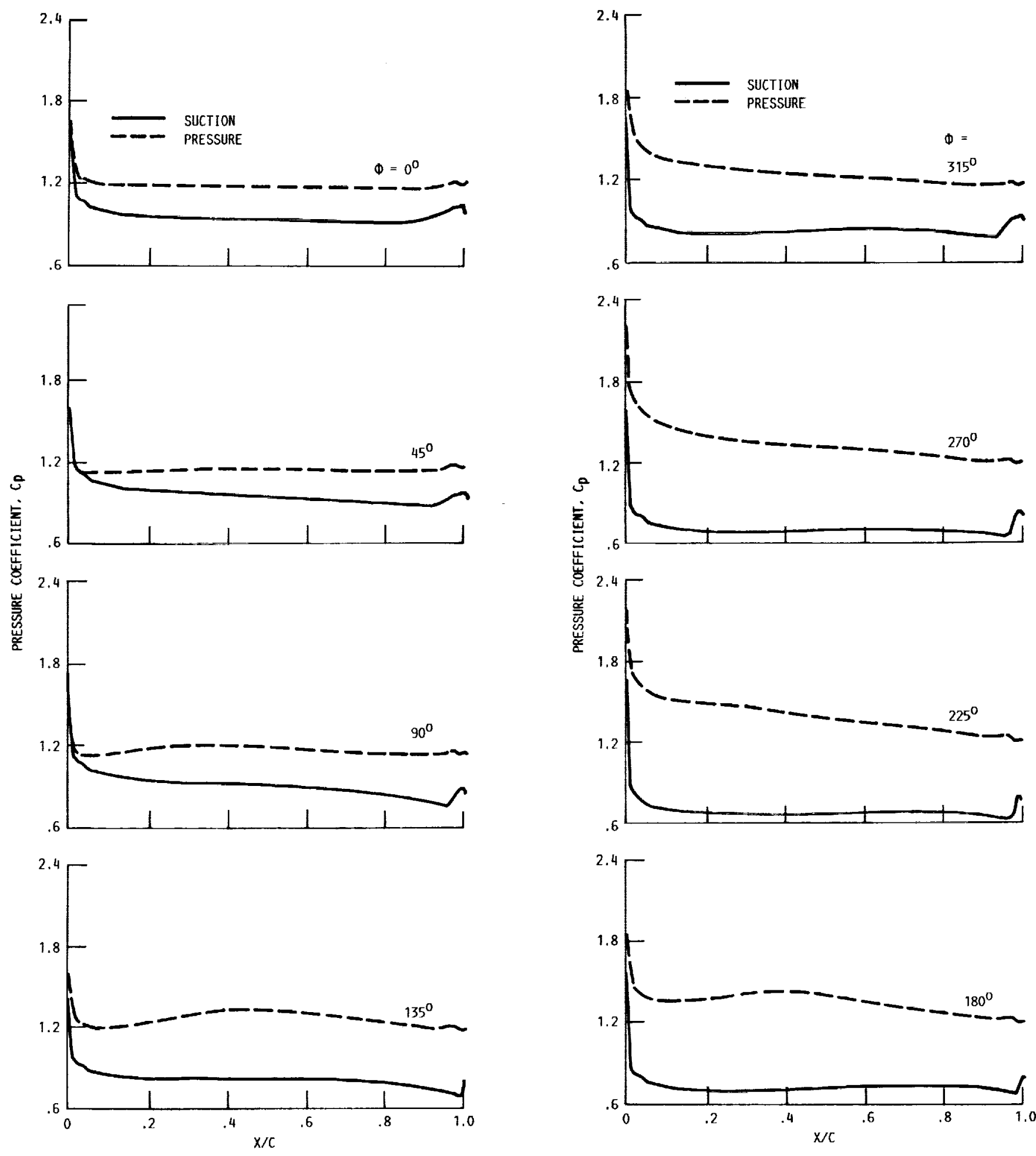

FIG. 10 AZIMUTHAL VARIATION OF BLADE SURFACE PRESSURES AT $r / R=0.96$.

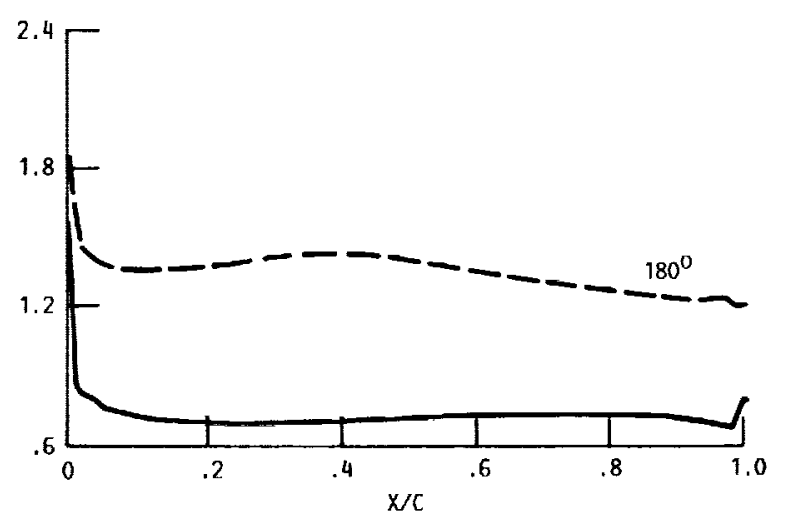

FIG. 10 CONCLUDED. 

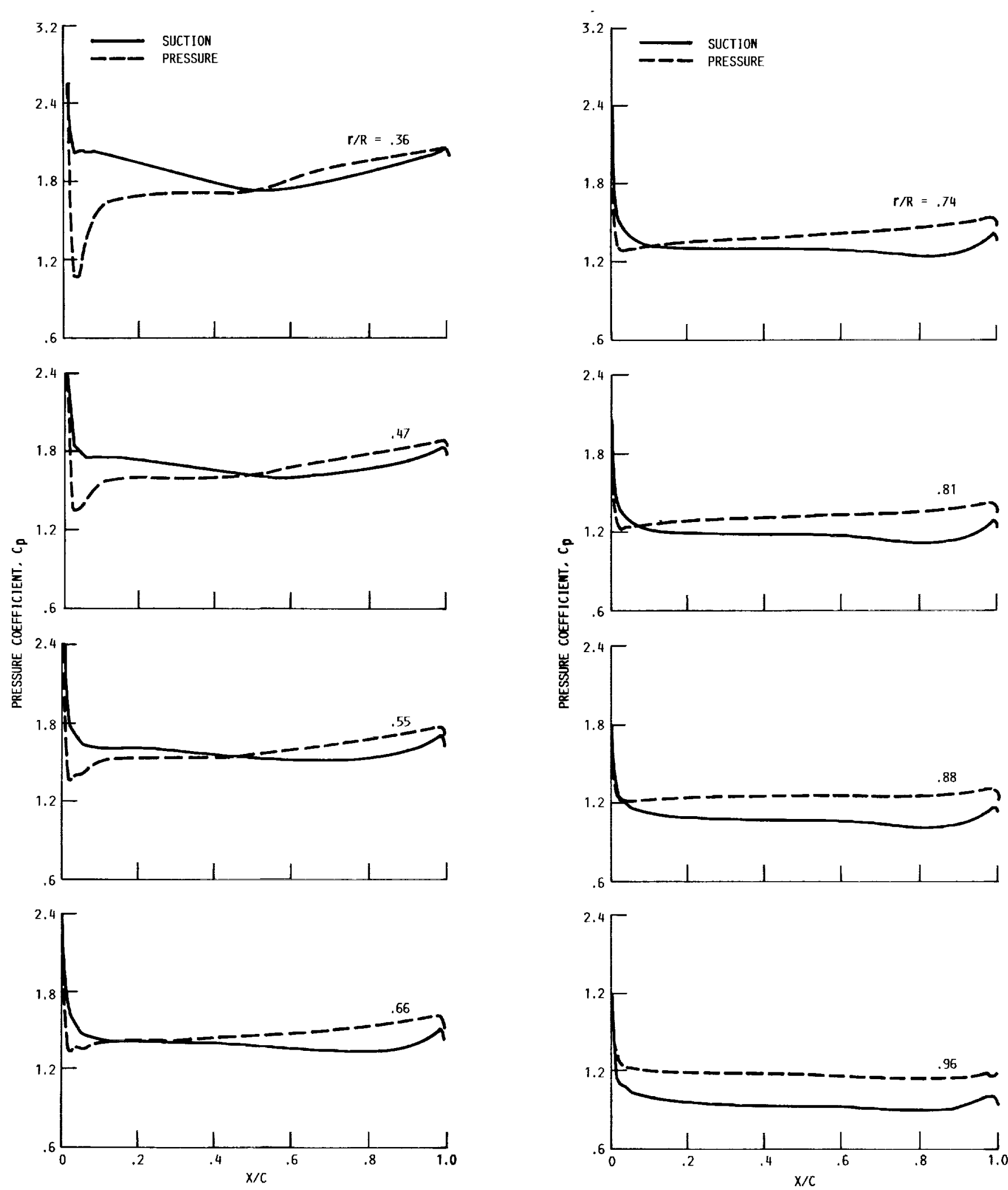

FIG, 11 SPANWISE VARIATION OF BLADE. SURFACE PRESSURES AT $=0^{\circ}$.

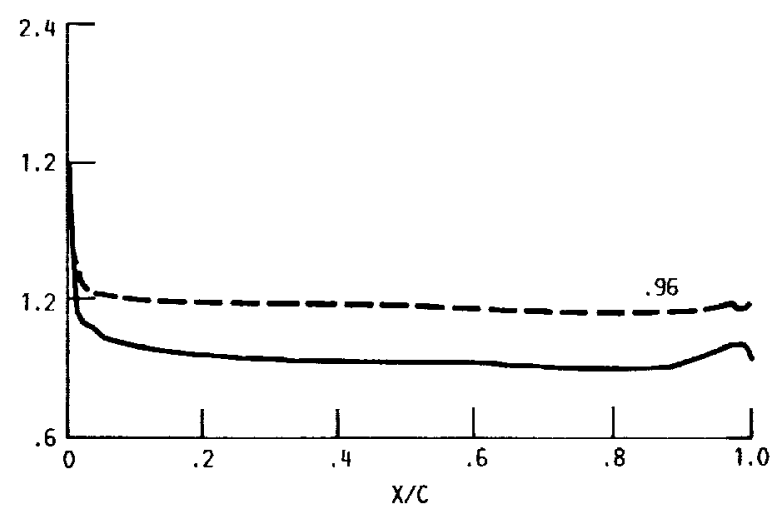

FIG. 11 CONCLUDED. 

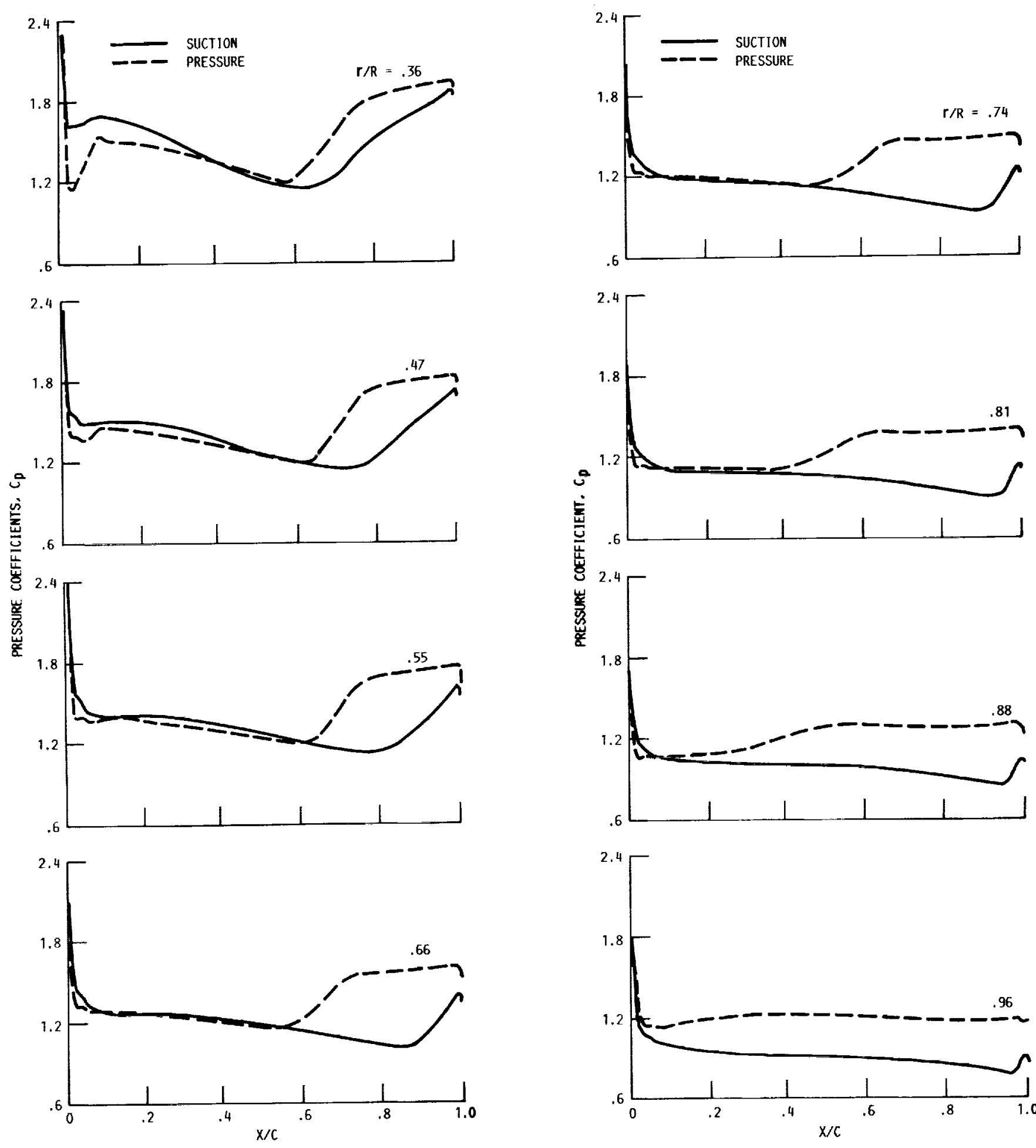

FI6. 12 SPANWISE Variation OF BLADE SURFACE. PRESSURES AT $=90^{\circ}$.

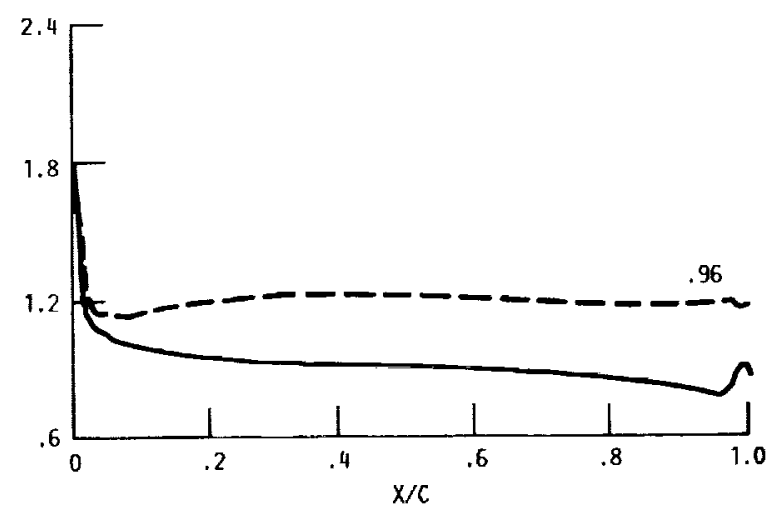

FI6. 12 COHCLUDED. 

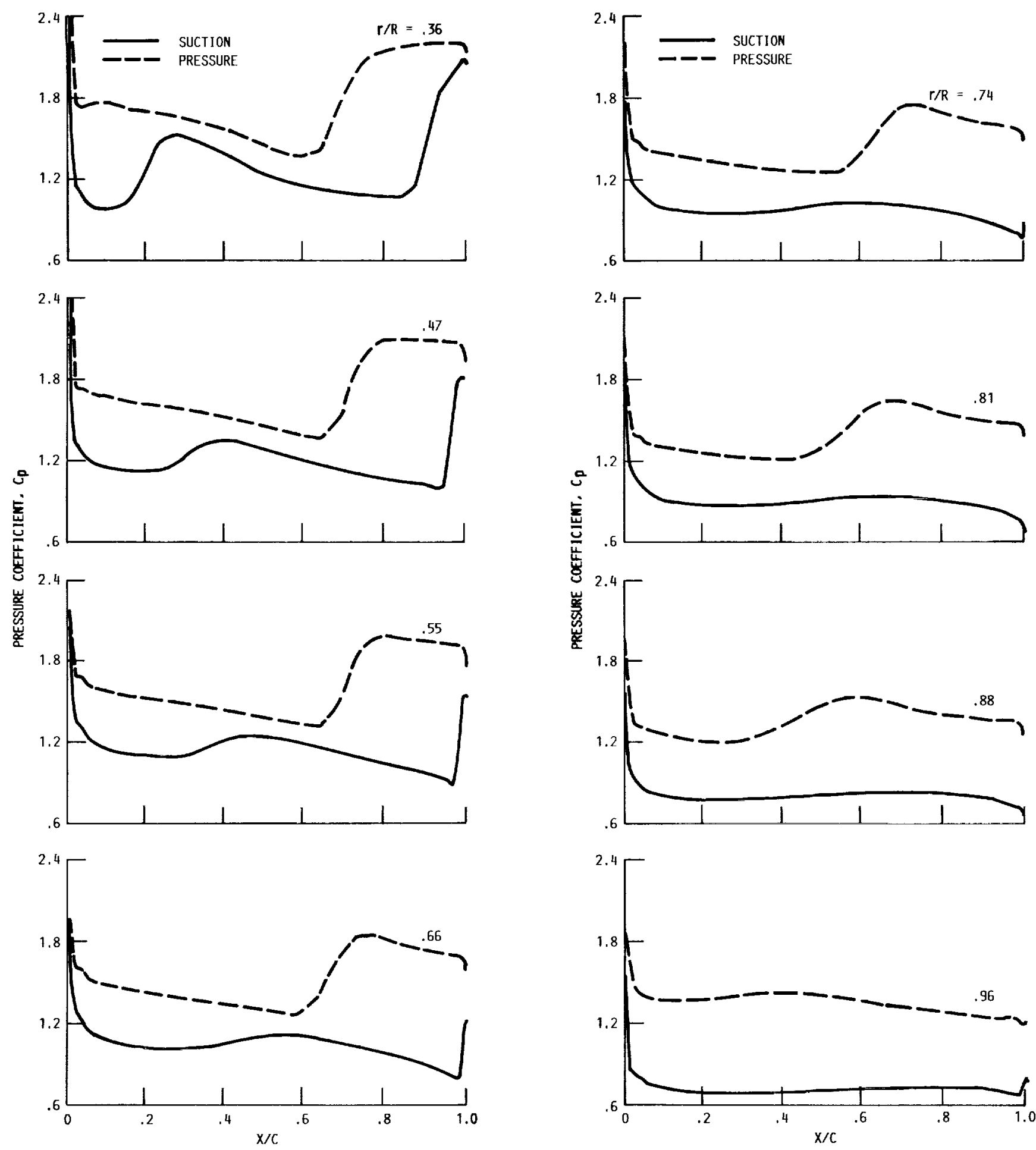

FIG. 13 SPANWISE VARIATION OF BLADE SURFACE PRESSURES AT $=180^{\circ}$.

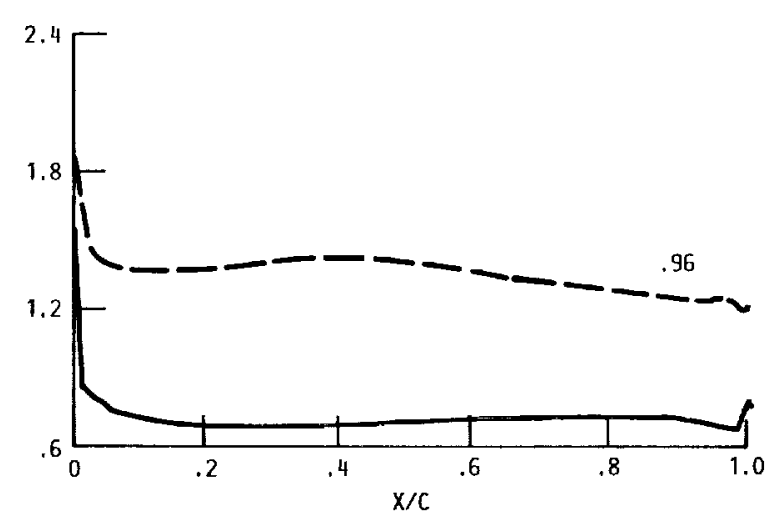

FIG, 13 CONCLUDED. 

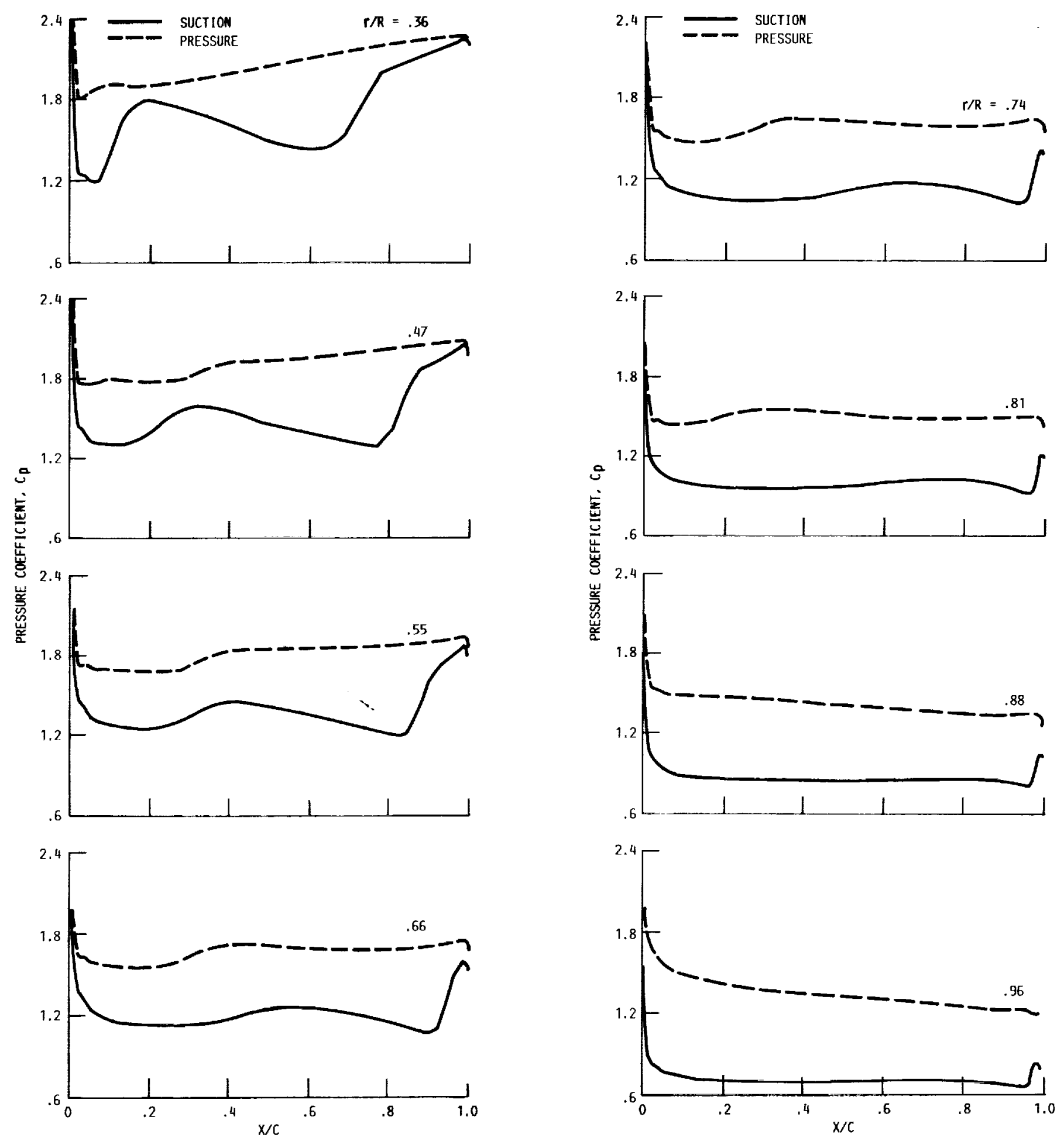

FIG. 14 SPANWISE VARIATION OF BLADE SURFACE PRESSURES AT $\oplus=270^{\circ}$.

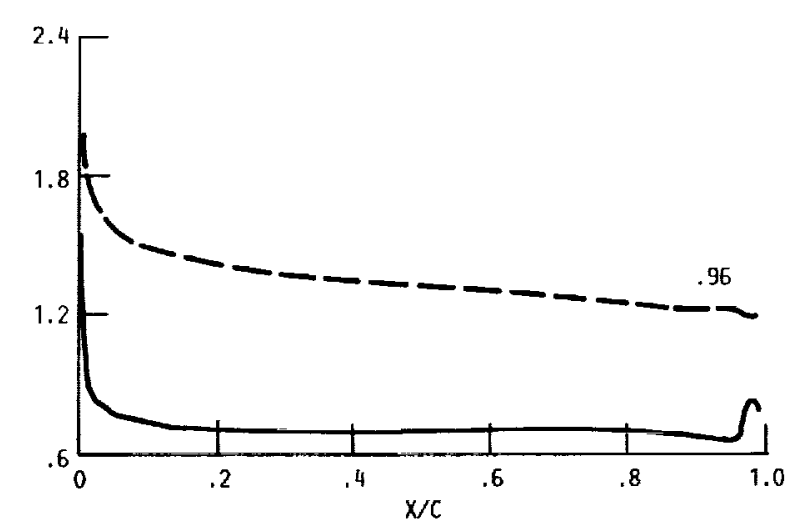

Fig. 14 CONCLUdED. 


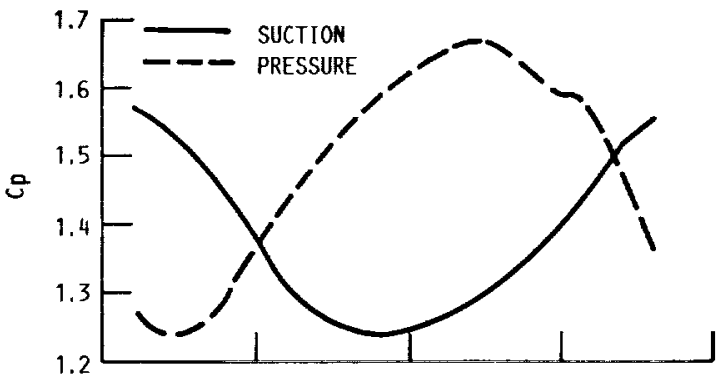

(a) $\mathrm{X} / \mathrm{C}=0.036$.

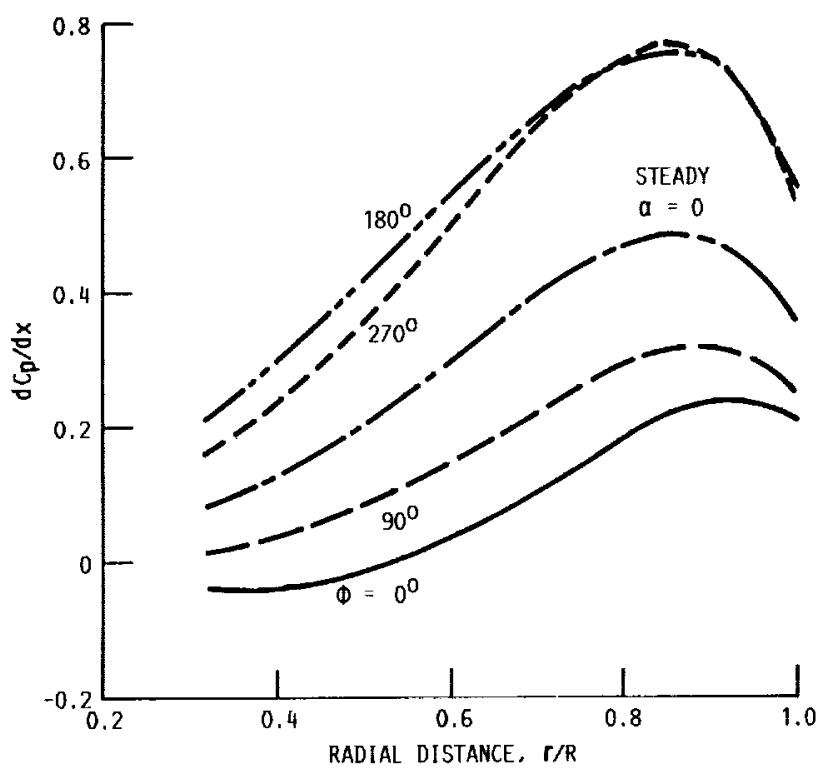

Fig. 15 ELEMENTAL POMER COEFFICIENT

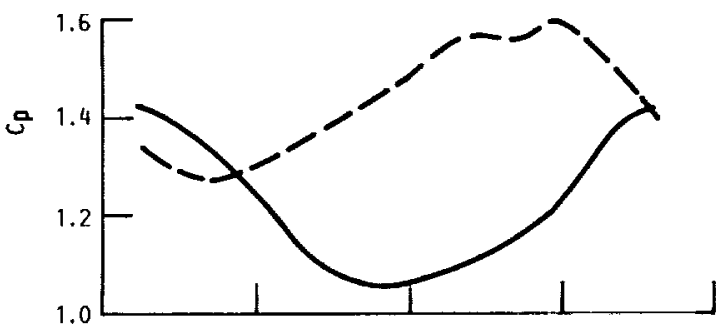

(b) $x / C=.125$.
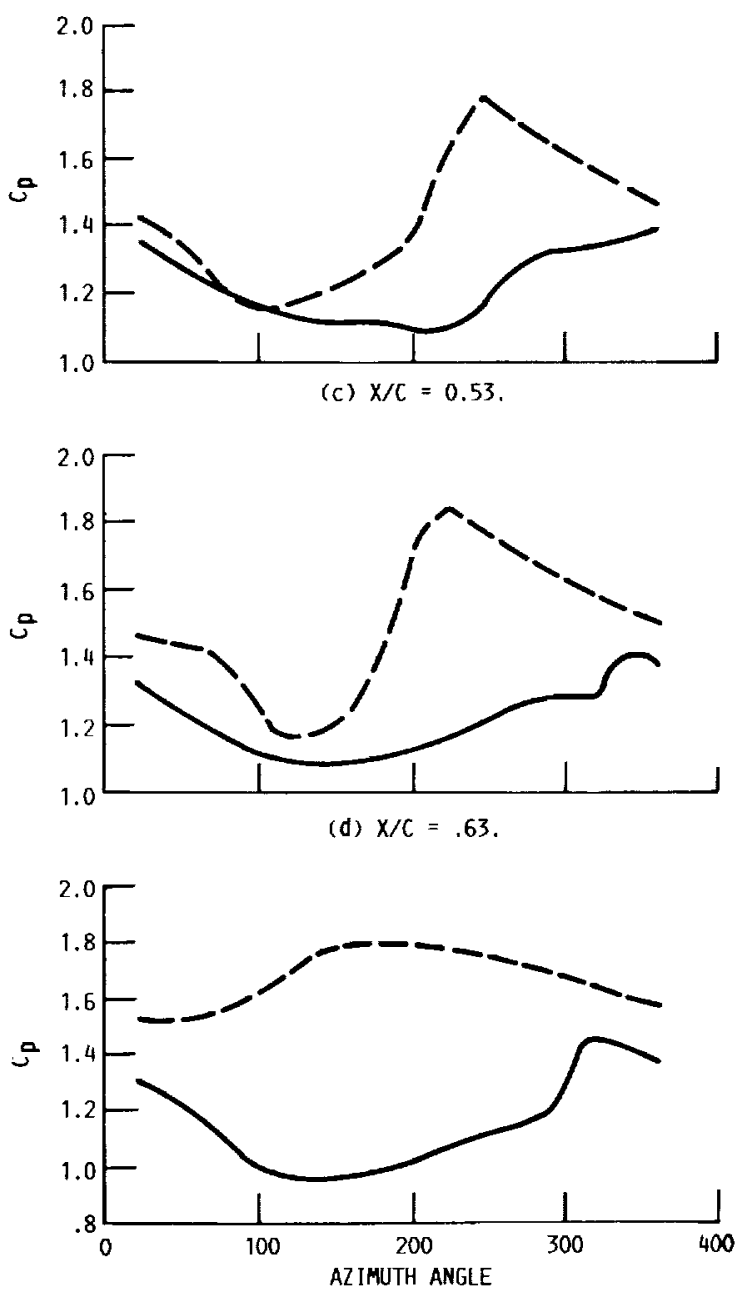

(e) $X / C=0.84$.

FIG, 16 BLADE-RESPONSE AT DIFFERENT AXIAL LOCATIOWS ON $\mathrm{T} / \mathrm{R}=0.66$. 


\begin{tabular}{|c|c|c|c|c|}
\hline \multicolumn{5}{|c|}{ Report Documentation Page } \\
\hline 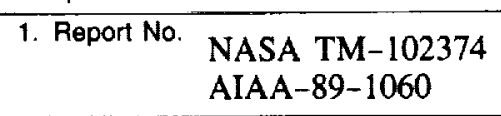 & \multicolumn{2}{|c|}{ 2. Government Accession No. } & \multicolumn{2}{|c|}{ 3. Reciplent's Catalog No. } \\
\hline \multicolumn{3}{|l|}{ 4. Title and Subtitle } & \multirow{2}{*}{\multicolumn{2}{|c|}{$\begin{array}{l}\text { 5. Report Date } \\
\text { November } 1989\end{array}$}} \\
\hline \multirow{2}{*}{\multicolumn{3}{|c|}{$\begin{array}{l}\text { Prediction of Unsteady Blade Surface Pressures on an } \\
\text { Advanced Propeller at an Angle of Attack }\end{array}$}} & & \\
\hline & & & \multicolumn{2}{|c|}{ 6. Performing Organization Code } \\
\hline \multirow{3}{*}{$\begin{array}{l}\text { 7. Author(s) } \\
\text { M. Nallasamy and J.F. Groene }\end{array}$} & & & \multirow{2}{*}{\multicolumn{2}{|c|}{$\begin{array}{l}\text { 8. Performing Organization Report No. } \\
\text { E-5108 }\end{array}$}} \\
\hline & & & & \\
\hline & & & \multicolumn{2}{|c|}{$\begin{array}{l}\text { 10. Work Unit No. } \\
535-03-01\end{array}$} \\
\hline \multirow{2}{*}{\multicolumn{3}{|c|}{$\begin{array}{l}\text { 9. Performing Organization Name and Address } \\
\text { National Aeronautics and Space Administration } \\
\text { Lewis Research Center } \\
\text { Cleveland, Ohio 44135-3191 }\end{array}$}} & \multicolumn{2}{|c|}{ 11. Contract or Grant No. } \\
\hline & & & \multirow{2}{*}{\multicolumn{2}{|c|}{$\begin{array}{l}\text { 13. Type of Report and Period Covered } \\
\text { Technical Memorandum }\end{array}$}} \\
\hline \multirow{2}{*}{\multicolumn{3}{|c|}{$\begin{array}{l}\text { 12. Sponsoring Agency Name and Address } \\
\text { National Aeronautics and Space Administration } \\
\text { Washington, D.C. 20546-0001 }\end{array}$}} & & \\
\hline & & & \multicolumn{2}{|c|}{ 14. Sponsoring Agency Code } \\
\hline \multicolumn{5}{|l|}{ 15. Supplementary Notes } \\
\hline \multicolumn{5}{|c|}{$\begin{array}{l}\text { A shortened version of this report was presented at the } 12 \text { th Aeroacoustics Conference sponsored by the } \\
\text { American Institute of Aeronautics and Astronautics, San Antonio, Texas, April 10-12, 1989. M. Nallasamy, } \\
\text { Sverdrup Technology, Inc., NASA Lewis Research Center Group, Cleveland, Ohio 44135; J.F. Groeneweg, } \\
\text { NASA Lewis Research Center. }\end{array}$} \\
\hline \multicolumn{5}{|c|}{$\begin{array}{l}\text { 16. Abstract } \\
\text { The paper considers the numerical solution of the unsteady, three-dimensional, Euler equations to obtain the } \\
\text { surface pressures of an advanced propeller at an angle of attack. The specific configuration considered is the SE } \\
\text { propeller at cruise conditions with a } 4.6^{\circ} \text { inflow angle corresponding to the }+2^{\circ} \text { nacelle tilt of the Propeller } \\
\text { Assessment (PTA) flight test condition. The results indicate nearly sinusoidal response of the blade loading, } \\
\text { angle of attack. For the first time, detailed variations of the chordwise loading as a function of azimuthal ang } \\
\text { are presented. It is observed that the blade is lightly loaded for part of the revolution and shocks appear from } \\
\text { hub to about } 80 \text { percent radial station for the highly loaded portion of the revolution. }\end{array}$} \\
\hline \multicolumn{2}{|c|}{$\begin{array}{l}\text { 17. Key Words (Suggested by Author(s)) } \\
\text { Advanced propellers; Aeroacoustics; Computational } \\
\text { acoustics, Turboprop; Noise; Propeller aerodynamics; } \\
\text { Unsteady Euler solutions }\end{array}$} & \multicolumn{3}{|c|}{$\begin{array}{l}\text { 18. Distribution Statement } \\
\text { Unclassified-Unlimited } \\
\text { Subject Category } 02\end{array}$} \\
\hline $\begin{array}{l}\text { 19. Security Classif. (of this report) } \\
\text { Unclassified }\end{array}$ & 20. Security Class & $\begin{array}{l}\text { f this page) } \\
\text { assified }\end{array}$ & $\begin{array}{c}\text { 21. No of pages } \\
26\end{array}$ & $\begin{array}{r}\text { 22. Price* } \\
\mathrm{A} 03\end{array}$ \\
\hline
\end{tabular}

